\title{
Statistical Comments on "Salivary Iron (Fe) Ion Levels, Serum Markers of Anemia and Caries Activity in Pregnant Women"
}

\section{Comentários estatísticos sobre "Níveis de íon ferro (Fe) salivar, marcadores séricos de anemia, e atividade de cárie em mulheres grávidas"}

\author{
Mehrdad Farrokhi ${ }^{1}$ Farnoosh Peykanpour ${ }^{2}$ \\ ${ }^{1}$ Medical Student, School of Medicine, Isfahan University of Medical \\ Sciences, Isfahan, Iran \\ ${ }^{2}$ Dentistry Student, School of Dentistry, Qom University of Medical \\ Sciences, Qom, Iran
}

Rev Bras Ginecol Obstet 2017;39:583.

Dear Editor,

We read with great interest a recent article by Costa et $\mathrm{al}^{1}$ entitled "Salivary iron (Fe) ion levels, serum markers of anemia and caries activity in pregnant women." In this prospective cohort, the authors aimed to investigate the association between salivary iron ( $\mathrm{Fe}$ ) and serum markers of anemia and the development of caries. In this regard, they assessed serum hemoglobin, ferritin, erythrocyte, serum Fe and salivary Fe levels in 59 women at three clinical times: up to the $16 \mathrm{~h}$ week of gestational age (T1), in the last trimester of pregnancy (T2), and postpartum (T3). The authors used analysis of variance (ANOVA) or Kruskal-Wallis tests for the comparative analysis of serum hemoglobin, ferritin, erythrocyte, serum Fe, and salivary Fe levels at the three clinical times. Therefore, in this cohort study, they investigated the differences between the levels of some biomarkers of the same pregnant women at different time points using independent tests. Analysis of variance and Kruskal-Wallis tests are used to compare the differences among the means of three or more independent (unrelated) groups, ${ }^{2,3}$ but the groups of the mentioned study are not independent, and the authors investigated some biomarkers of 59 pregnant women at 3 different time points. Therefore, the groups of
Address for correspondence Mehrdad Farrokhi, Medical Students, Mother Boulevard, Golpayegan, Isfahan, Iran (e-mail: mehrdadfarokhi72@yahoo.com).

this study are completely dependent. After the assessment of the distribution of the numerical variables, the authors must use repeated measures ANOVA or the Friedman test for the comparison of the means of the biomarkers at three clinical times. Taken together, we believe that most of the statistical tests used in this study are inappropriate, and the authors' valuable study could be better used as citable experimental evidence if analyzed with appropriate statistical tests.

Conflicts of Interest

The authors declare that there are no conflicts of interest regarding the publication of this letter.

\section{References}

1 Costa EM, Azevedo JAP, Martins RFM, et al. Salivary iron (Fe) ion levels, serum markers of anemia and caries activity in pregnant women. Rev Bras Ginecol Obstet 2017;39(03):94-101

2 Gaddis ML. Statistical methodology: IV. Analysis of variance, analysis of covariance, and multivariate analysis of variance. Acad Emerg Med 1998;5(03):258-265

3 Farrokhi M. Sema3A and multiple sclerosis. Gene 2017;615:41 received

May 30, 2017

accepted

June 30, 2017

published online

August 7, 2017
DOI https://doi.org/

10.1055/s-0037-1605374. ISSN 0100-7203.
Copyright $(2017$ by Thieme Revinter

Publicações Ltda, Rio de Janeiro, Brazil
License terms

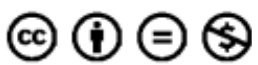

